\title{
Activity Engagement of Aging Retirees in South Korea
}

\author{
SANG-Heon Lee, OT, PhD ${ }^{1)}$ \\ 1) Department of Occupational Therapy, College of Medical Science, Soon Chun Hyang University: \\ 646 Eupnae-ri, Shinchang-myeon, Asan-si, Chungnam 336-745, Republic of Korea
}

\begin{abstract}
Purpose] The purpose of this study was to analyze the activity engagement of the retiree population in South Korea. [Methods] The Korean-Activity Card Sort (K-ACS) was used to collect research data. A One-way ANOVA and post-hoc comparisons showed significant group effects among three age groups. The independent t-tests was used to analyze the differences in mean retained level of activity (MRA) between men and women. [Results] The one-way ANOVA showed statistically significant differences in MRA among different age groups. Scheffé's test revealed a statistically significant decrease in MRA in Group A, aged more than 75 years, as compared to the other two age groups. When participants were divided by gender, MRA of instrumental activities showed a statistically significant difference between the 65-74 years group and the 55-65 years group, but no difference in females of the leisure activities among the age groups. The independent t-tests demonstrated significant gender differences in MRA of activity of the 55-64 years group. [Conclusion] These findings suggest that health professionals should monitor the changes in retained level of activity after age 75 , to maintain their engagement, and the importance of age-, gender- and activity-specific analyses in order to identifying patterns of activity engagement. Key words: Activity engagement, Korean-activity card sort, Older adults
\end{abstract}

(This article was submitted Jul. 25, 2013, and was accepted Sep. 1, 2013)

\section{INTRODUCTION}

When the baby boomer generation began to retire, they became a topic of interest in South Korea. As the retired population of South Korea ages, the older adults population continues to increase faster than in any other country ${ }^{1)}$. As people age, their activity engagement may decrease or change.

Continued activity engagement has showed positive effects on healthy life, mental health and quality of life. The group based activities in community centres have been associated with improvements in the health and well being of adults who have previously experienced poor health and other forms of social disadvantage ${ }^{2}$. Continued work involvement or volunteerism provides opportunities for social interaction and engagement, and may be associated with enhanced mental well-being of older adults ${ }^{3)}$. Increases in physical activity has been associated with higher physical self-worth and fewer disability limitations which have been associated with greater life satisfaction ${ }^{4}$.

For aging and activity engagement studies to be successful, the assessment tool must cover a lot of activities. Ideally, health is a state of adequate physical and mental

Corresponding author. Sang-Heon Lee (E-mail: sangheon@ sch.ac.kr)

(C2014 The Society of Physical Therapy Science. Published by IPEC Inc. This is an open-access article distributed under the terms of the Creative Commons Attribution Non-Commercial No Derivatives (by-ncnd) License $<$ http://creativecommons.org/licenses/by-nc-nd/3.0/>. independence in activities of daily living ${ }^{5)}$. In addition, voluntary work, cultural activities, holiday, sports, reading books, hobbies and shopping are found to be successful predictors of the social connectedness of older people ${ }^{6}$.

The Activity Card Sort (ACS) is a standardized assessment tool that evaluates the amount and level of involvement in various activities ${ }^{7}$. The ACS consists of labeled photographs of older people participating in a range of activities and has multiple benefits over existing measures of participation of older adults, including ease of use, lack of dependency on literacy levels, and the inclusion of a broad range of culturally relevant activities ${ }^{8,9)}$. Originally developed in the USA, the ACS now has versions designed for use in Israel, Hong Kong, Australia, and South Korea ${ }^{10-12)}$.

The present study aimed to gain and understanding of activity engagement of aging retirees. K-ACS data was analysed to examine the effect of aging on activity engagement.

\section{SUBJECTS AND METHODS}

Data were collected by seven senior university students, who had completed four months of clinical practice and were trained to administer and score the K-ACS.

Eligible participants were individuals over 55 years old who could write and communicate in Korean. Candidates were excluded if they had obvious auditory, visual, or cognitive impairments ${ }^{8}$. All participants provided their informed consent before participating in this study. The study methods and procedures were approved by the Institutional Review Board of Soonchunhyang University.

The K-ACS has three versions: institutional, recovery, 
and community living. This study used the community living version. The community living version requires participants to sort 67 photographs of activities (33 photographs illustrating instrumental activities, activities to support daily life within the home and community; 18 photographs illustrating leisure activities, nonobligatory activities that is intrinsically motivated and engaged in during discretionary time; and 16 photographs illustrating social activities, activities that are characteristic and expected of an individual in a given position within a social system) into 5 categories: "Never done," "Given up," "Do now," "Do less," or "New activity." The retained level of activity engagement (\%) is calculated as follows:

Level of current activity = values of "Do now" + values of "Do less"

Level of previous activity = values of "Done previously" column (i.e., "Do now"," Do less" and "Given up")

Retained level of activity (by percentage) = level of current activity/level of previous activity $\times 100 \%$

Data were analyzed using SPSS version 20.0. Descriptive statistics were used to describe the participant demographics. Participants were divided into three age groups: $\geq 75$ years (Group A), 65-74 years (Group B), and 5564 years (Group C). A One-way ANOVA was used to compare the mean retained level of activity (MRA) among the three age groups, and Scheffe's test was used for post-hoc analyses. The independent $t$-tests was used to examine the significance of gender differences. 95\% CI was used and the' results were accepted as significant if $\mathrm{p}<0.05$.
Table 1. General characteristics of the participants $\quad(n=386)$

\begin{tabular}{|c|c|c|c|}
\hline & & Number & Percent (\%) \\
\hline \multirow{2}{*}{ Sex } & Male & 190 & 49.2 \\
\hline & Female & 196 & 50.8 \\
\hline \multirow{3}{*}{ Age } & $55-64$ & 125 & 32.4 \\
\hline & $65-74$ & 130 & 33.7 \\
\hline & 75 & 131 & 33.9 \\
\hline \multirow{7}{*}{$\begin{array}{l}\text { Highest } \\
\text { education }\end{array}$} & No education & 55 & 14.2 \\
\hline & Elementary School & 95 & 24.6 \\
\hline & Middle School & 82 & 21.2 \\
\hline & High School & 118 & 30.6 \\
\hline & College & 11 & 2.8 \\
\hline & University & 20 & 5.2 \\
\hline & Graduate School & 5 & 1.3 \\
\hline \multirow{2}{*}{ Residence } & Urban & 279 & 72.3 \\
\hline & Rural & 107 & 27.7 \\
\hline \multirow{4}{*}{$\begin{array}{l}\text { Self-rated } \\
\text { health }\end{array}$} & Excellent & 28 & 7.3 \\
\hline & Good & 132 & 34.2 \\
\hline & Average & 147 & 38.1 \\
\hline & Poor & 79 & 20.5 \\
\hline \multirow{4}{*}{$\begin{array}{l}\text { Self-rated } \\
\text { activities of } \\
\text { daily living } \\
\text { difficulty }\end{array}$} & Not at all & 60 & 15.5 \\
\hline & Not very & 143 & 37.1 \\
\hline & Neutral & 93 & 24.1 \\
\hline & Somewhat & 90 & 23.3 \\
\hline \multirow{2}{*}{$\begin{array}{l}\text { Living } \\
\text { arrangement }\end{array}$} & With spouse & 282 & 73.1 \\
\hline & Without spouse & 104 & 26.9 \\
\hline
\end{tabular}

Table 2. The Comparison of the mean retained level of activities by age

\begin{tabular}{lccc}
\hline & \multicolumn{3}{c}{ Total } \\
\cline { 2 - 4 } & $\mathrm{A}^{\mathrm{a}}(\mathrm{n}=131)$ & $\mathrm{B}^{\mathrm{b}}(\mathrm{n}=130)$ & $\mathrm{C}^{\mathrm{c}}(\mathrm{n}=125)$ \\
\hline Instrumental activities & $68.1 \pm 20.6$ & $81.5 \pm 16.5$ & $86.6 \pm 16.0^{* *}$ \\
Leisure activities & $71.4 \pm 20.6$ & $83.2 \pm 19.5$ & $84.4 \pm 18.3^{* *}$ \\
Social activities & $66.1 \pm 26.3$ & $82.3 \pm 23.3$ & $84.1 \pm 20.0^{* *}$ \\
\hline
\end{tabular}

a: $\geq 75$ years old, ${ }^{\text {b }}$ : 65-74 years old, ${ }^{\text {c }: ~ 55-64 ~ y e a r s ~ o l d, ~} * *:<0.01$ compared within activities

Table 3. The Comparison of the mean retained level of activities by age and sex

\begin{tabular}{llccc}
\hline & & \multicolumn{3}{c}{ Age } \\
\cline { 3 - 5 } & & $\mathrm{A}^{\mathrm{a}}$ & $\mathrm{B}^{\mathrm{b}}$ & $\mathrm{C}^{\mathrm{c}}$ \\
\hline & & $66.1 \pm 23.67$ & $7.0 \pm 17.7$ & $90.1 \pm 12.1^{* *},++$ \\
Instrumental & Male & $(\mathrm{n}=41)$ & $(\mathrm{n}=77)$ & $(\mathrm{n}=72)$ \\
activities & & $69.0 \pm 19.2$ & $82.5 \pm 14.6^{* *}$ & $81.8 \pm 19.2$ \\
& Female & $(\mathrm{n}=90)$ & $(\mathrm{n}=53)$ & $(\mathrm{n}=53)$ \\
\hline & & $69.2 \pm 20.7$ & $85.5 \pm 18.2$ & $88.5 \pm 13.4^{* *},++$ \\
Leisure & Male & $(\mathrm{n}=41)$ & $(\mathrm{n}=77)$ & $(\mathrm{n}=72)$ \\
activities & & $72.3 \pm 20.7$ & $79.8 \pm 20.9$ & $79.0 \pm 22.4$ \\
& Female & $(\mathrm{n}=90)$ & $(\mathrm{n}=53)$ & $(\mathrm{n}=53)$ \\
\hline \multirow{3}{*}{ Social } & \multirow{2}{*}{ Male } & $67.7 \pm 23.8$ & $82.1 \pm 23.1^{* *}$ & $81.2 \pm 22.4^{++}$ \\
activities & & $(\mathrm{n}=41)$ & $(\mathrm{n}=77)$ & $(\mathrm{n}=72)$ \\
& Female & $65.4 \pm 27.5$ & $82.6 \pm 23.7^{* *}$ & $79.0 \pm 22.4$ \\
& & $(\mathrm{n}=90)$ & $(\mathrm{n}=53)$ & $(\mathrm{n}=53)$ \\
\hline
\end{tabular}

a: $\geq 75$ years old, ${ }^{\text {b: }} 65-74$ years old, ${ }^{\text {c }:}$ 55-64 years old

$* *:<0.01$ compared within activities, ${ }^{++}:<0.01$ compared between male and female 


\section{RESULTS}

Three hundred eighty-six healthy adults participated in this study. Participants were assigned to the $\mathrm{A}, \mathrm{B}$, or $\mathrm{C}$ groups to compare the mean levels of activity retained with age. Most participants had completed elementary school $(85.75 \%)$ and lived in urban communities $(72.28 \%)$. Participants rated their health status on a five-point scale, ranging from "Excellent" to "Poor." The same scale was also used to rate each participant's difficulty with activities of daily living, from "Not at all" to "Somewhat." Most participants reported living with a spouse $(73.06 \%)$ (Table 1$)$.

MRA decreased with age (Table 2). There were significant differences in the MRA between Group A and the other age groups (instrumental activities, $\mathrm{F}=36.81, \mathrm{p}<0.01$ : leisure activities, $\mathrm{F}=17.71, \mathrm{p}<0.01$, social activities, $\mathrm{F}=23.24$, $\mathrm{p}<0.01$ ), but no significant differences were found between Groups B and C (Table 3). When participants were divided by gender, the same results were obtained except for the instrumental activities of males and the leisure activities in females. There were significant differences in MRA of instrumental activities between group $\mathrm{B}$ and $\mathrm{C}$ for males, but there were no age differences in females of leisure activities. The independent $t$-tests demonstrated significant gender differences of the MRA in Group C (Table 3).

\section{DISCUSSION}

Activity engagement is a natural means of maintaining physical and mental function, and experiencing well being ${ }^{10)}$. However, activity limitation is a frequent geriatric issue with considerable individual and societal impacts. People living with activity limitations may be less likely to experience happiness or life satisfaction, which can have a negative effect on their quality of life ${ }^{13}$. However, little is known about the age profile of activity engagement in the South Korean retiree population with age.

This study found that activity engagement decreased with age ${ }^{14)}$. Examining the results of each age group, the most significant changes appeared mainly in Group A. This finding highlights the need for care for older adults over 75 years to maintain their MRA. It is important to recognize that when activity participation is changing, there may be health issues that make older adults vulnerable to functional decline ${ }^{15)}$. In contrast, engagement in activity acts as a buffer against physical decline in later life ${ }^{16,17)}$. It is important to know that engagement in activity provides a health benefit that is as important as physical exercise ${ }^{18)}$.

In addition, The decreased engagement with age of males in instrumental activities, continued engagement of females in leisure activities, and significant gender differences in MRA in Group C, suggest the importance of age-, genderand activity-specific analyses in order to identify patterns of engagement. Daily activities vary greatly according to interests and life circumstances ${ }^{15}$. Activity choices are affected by changes of life roles because of family dynamics, changes in living situation, and the deaths of family and friends ${ }^{19)}$

This study has several possible limitations. All participants were volunteers; thus, our sample may not be representative of the entire post-retirement aging popula- tion. Second, the K-ACS is a self-report measure, so it may not accurately reflect actual engagement. In addition, the K-ACS measures the numbers of activities, but does not measure the intensity, frequency, or duration of each activity ${ }^{20)}$. Finally, when calculating the retained level of activity, engagement in new activities was not included in the analyses to identify decreases from previous levels of activity. Therefore, the mean level of current activity could be higher if new activities were included in the calculations performed using the original equation.

\section{ACKNOWLEDGEMENT}

This work was supported by the Soonchunhyang University Research Fund.

\section{REFERENCES}

1) Chung SD, Koo MJ: Factors influencing depression: a comparison among babyboomers, the pre-elderly, and the elderly. Int J Welf Aged, 2011, 52: $305-324$.

2) Jones M, Kimberlee R, Deave T, et al.: The role of community centrebased arts, leisure and social activities in promoting adult well-being and healthy life styles. Int J Environ Res, 2013, 10: 1948-1962.

3) Schwingel A, Niti NM, Tang C, et al.: Continued work employment and volunteerism and mental well-being of older adults: Singapore longitudinal studies. Age Ageing, 2009, 38: 531-537. [Medline] [CrossRef]

4) Phillips SM, Wójcicki TR, McAuley E: Physical activity and quality of life in older adults: an 18-month panel analsis. Qual Life Res, 2012 [Epub ahead of print].

5) Rattan SI: Healthy ageing, but what is health? Biogerontol, 2013, [Epub ahead of print].

6) Toepoel V: Ageing, leisure, and social connectedness: how could leisure help reduce social isolation of older people? Soc Indic Res, 2013, 113: 355372. [Medline] [CrossRef]

7) Sachs D, Josman N: The activity card sort: a factor analysis. OTJR (Thorofare, NJ), 23: 165-174 (thorofare NJ).

8) Doney RM, Packer TL: Measuring changes of activity participation of older Australians: validation of the Activity Card Sort-Australia. Australas J Ageing, 2008, 27: 33-37. [Medline] [CrossRef]

9) Baum CM, Edward D: Activity Card Sort. St. Louis: Washington University School of Medicine, 2001

10) Hartman-Maeir A, Soroker N, Ring H, et al.: Activities, participation and satisfaction one-year post stroke. Disabil Rehabil, 2007, 29: 559-566. [CrossRef]

11) Chan V, Chung J, Packer T: Validity and reliability of the activity card Sort-Hong Kong version. OTJR (Thorofare, NJ), 2006, 32: 238-245 (thorofare $\mathrm{N} \mathrm{J}$ ).

12) Lee S: Development, reliability, and validity of the Korean Activity Card Sort. Seoul: Yonsei University, 2009.

13) Levasseur M, Desrosiers J, St-Cyr Tribble D: Do quality of life, participation and environment of older adults differ according to level of activity? Health Qual Life Outcomes, 2008, 6: 30. [Medline] [CrossRef]

14) Katz N, Karpin H: Lak Arit: participation in occupational performance: reliability and validity of the activity card sort. OTJR (Thorofare, NJ), 2003, 23: 10-17 (thorofare $\mathrm{N} \mathrm{J}$ ).

15) Baum CM, Edwards D: Activity Card Sort. Bethesda: AOTA, 2008.

16) Glass TA, Seeman TE, Herzog AR, et al.: Change in productive activity in later adulthood: MacArthur studies of successful aging. J Gerontol, 1995, 50B: S65-S76. [CrossRef]

17) Mendes de Leon CF, Class TA, Berkman LF: Social engagement and disability in a community population of older adults. Am J Epidemiol, 2003, 157: 633-642. [Medline] [CrossRef]

18) Glass TA, de Leon CM, Marottoli RR, et al.: Population-based study of social and productive activities as predictors of survival among elderly Americans. BMJ, 1999, 319: 478-483. [Medline] [CrossRef]

19) Smith NR, Kielhofner G, Watts JH: The relationships between volition, activity pattern, and life satisfaction in the elderly. Am J Occup Ther, 1986, 40: 278-283. [Medline] [CrossRef]

20) Hildebrand M, Brewer M, Wolf T: The impact of mild stroke on participation in physical fitness activities. Stroke Res Trea, 2012, 54862. 